\title{
6
}

\section{DENOMINAÇÕES EM GALEGO E EM PORTUGUÊS PARA A BRINCADEIRA DE "PEGAR COM OLHOS VENDADOS"1}

\section{DENOMINATIONS IN GALICIAN AND IN PORTUGUESE FOR THE GAME OF “PICKING WITH BLIND EYES”}

\author{
Silvana Soares Costa Ribeiro ${ }^{2}$ \\ Universidade Federal da Bahia \\ Jacyra Andrade Mota ${ }^{3}$ \\ Universidade Federal da Bahia/CNPq \\ Aparecida Negri Isquerdo 4 \\ Universidade Federal de Mato Grosso do Sul/CNPq
}

Resumo: $\mathrm{O}$ artigo analisa denominações, em galego e em português do Brasil (PB) e europeu (PE), para "a brincadeira em que uma criança, com os olhos vendados, tenta pegar as outras", com base em dados extraídos do Tesouro do léxico patrimonial galego e português, de cinco atlas linguísticos, e de outras cinco obras originadas de trabalhos de pós-graduação. A amostra reuniu formas lexicais como cabra-cega, cobra-cega, gata-cega, pita-cega, galinha-cega, compostas, em sua maioria, com nomes de animais, razão de terem sido examinadas sob o ponto de vista motivacional, com ênfase na perspectiva do zoomorfismo. O estudo demonstrou a importância de bases lexicais que incorporam léxicos produzidos em diferentes sincronias da história da língua, o que permite a comparação, a análise da natureza linguística e das motivações semânticas identificadas na forma de nomear, no caso, a brincadeira "cabra-cega".

Palavras-chave: Cabra-cega; Pita-cega; Brincadeiras infantis; Atlas linguísticos; Tesouro do léxico patrimonial galego e português.

${ }^{1}$ Dedicamos o artigo à saudosa profa. Maria del Rosário Suárez Albán, docente aposentada da disciplina Língua Portuguesa do Instituto de Letras, amiga das autoras, fundadora do CELGA (Centro de Estudos da Língua e Cultura Galegas), que recebeu, post mortem, a Comenda Dois de Julho da Assembleia Legislativa da Bahia em 29 de março de 2019.

2 silvanar@ufba.br

3 jacymota@gmail.com

${ }_{4}^{4}$ aparecida.isquerdo@gmail.com 
Abstract: In this article, we analyze denominations, in Galician and Brazilian Portuguese (PB) and European (PE), for "the game in which a child, blindfolded, tries to catch the others", based on data extracted from the "Tesouro do léxico patrimonial galego e português" (Galician and Portuguese word bank), linguistic atlases, including the Atlas Linguístico do Brasil (Linguistic Atlas of Brazil), and other works. The sample included lexical forms such as cabra-cega (blindman's buff), cobra-cega (blind snake), gata-cega (blind cat), pita-cega (pita-blind), galinha-cega (blind chicken), mostly composed of animal names, reason for having been examined under the motivational point of view and with emphasis on the zoomorphism perspective. The study demonstrates the importance of lexical bases that incorporate lexicons produced in different synchrony of the history of the language, which allows the comparison, the analysis of the linguistic nature and the semantic motivations identified in the way of naming, in this case, the game "cabra-cega" (blindman's buff).

Keywords: Blindman's buff; Children's games; Linguistic atlases; Galician and Portuguese word bank.

\section{INTRODUÇÃO}

A língua, vista como patrimônio imaterial de uma sociedade, guarda no léxico o conhecimento adquirido e mantido pelos seus usuários. O léxico, desse ponto de vista, é também o grande repositório das tradições, dos eventos culturais, além da sua função básica de nomear todos os elementos da realidade. Reconhecidamente, os nomes dos brinquedos e das brincadeiras infantis são importantes elementos de estudo, visto que materializam vivências dos falantes nas diferentes fases de aquisição da linguagem e do léxico. Optamos aqui por trazer para a discussão denominações registradas em galego e em português do Brasil (PB) e europeu (PE) atribuídas à brincadeira infantil conhecida como pitacega (galego e português europeu) ${ }^{5}$ e como cabra-cega (português europeu e brasileiro) ${ }^{6}$. Partimos do pressuposto de que, além de ultrapassarem os limites de línguas, no caso, as românicas, os nomes da brincadeira em causa deixam transparecer tanto formas transplantadas pelo colonizador português quanto criações locais empregadas por falantes das diferentes regiões brasileiras para nomear um tipo de brincadeira que tem se perpetuado ao longo dos séculos.

\footnotetext{
5 Em galego, pita nomeia (i) galinha nova que ainda não chegou à idade de pôr ovos (franga/pintainha em português) ou (2) galinha adulta.

${ }^{6}$ Cabra-cega, em galego, nomeia um tipo de inseto - zapatero.
} 
O trabalho aqui apresentado contém dados documentados no Tesouro do léxico patrimonial galego e português (TLPGP) (ÁLVAREZ, 2021), doravante Tesouro ou TLPGP, e em alguns atlas linguísticos produzidos com dados do PB, a exemplo do Atlas Linguístico do Brasil - ALiB (CARDOSO et al., 2014). As obras são detalhadas na seção 1: “Convidando os participantes para a brincadeira: constituição do corpus de análise e questões teórico-metodológicas".

Em “Tirando a venda dos olhos: descrição linguística e hipóteses interpretativas", seção 2, apresentamos a análise linguística das denominações catalogadas (cabra-cega, cobra-cega, gata-cega, pata-cega, pita-cega, galinha cega, vacacega, dentre outras) numa abordagem motivacional, com ênfase na perspectiva zoomórfica, ou seja, denominações que associam o nome da brincadeira a um tipo de animal.

$\mathrm{Na}$ seção 3, intitulada "Vamos continuar a brincadeira? Breves considerações finais", destacamos três aspectos da abordagem empreendida: (i) a importância do Tesouro enquanto base lexical que armazena obras lexicográficas com características de cunho dialetal produzidas a partir de inventários léxicos do $\mathrm{PB}, \mathrm{PE}$ e galego e dados oriundos de atlas linguísticos como fornecedores, dentre outras contribuições, de amostras representativas de normas lexicais, fontes essas produzidas em momentos diversos da história das línguas portuguesa e galega; (ii) a pertinência da comparação entre recortes léxicos de algumas línguas românicas, no que se refere às denominações para uma brincadeira infantil tomada aqui como elemento da cultura e como mecanismo de resgate de aspectos da formação da norma lexical do PB em espaços variados do território brasileiro; e (iii) a importância da análise da natureza linguística e das motivações semânticas identificadas na forma de nomear, no caso, a brincadeira "cabra-cega" que, no seu conjunto, reúne tanto formas transplantadas pelo colonizador português quanto criações locais 
empregadas por falantes das diferentes regiões brasileiras para denominar um tipo de brincadeira que tem se mantido no universo lúdico infantil.

\section{CONVIDANDO OS PARTICIPANTES PARA A BRINCADEIRA: CONSTITUIÇÃO DO CORPUS DE ANÁLISE E QUESTÕES TEÓRICO-METODOLÓGICAS}

Como anteriormente assinalado, os dados lexicais analisados foram obtidos por meio de consulta ao Tesouro e a alguns atlas linguísticos, a exemplo do Atlas Linguístico do Brasil, dentre outros publicados no Brasil e ainda não incorporados ao Tesouro. A opção pela consulta a essa base digital de dados lexicais tem por finalidade dar luz ao que vem sendo produzido por equipes de pesquisadores galegos, portugueses e brasileiros empenhados em construir um Tesouro do léxico patrimonial galego e português que agregue pesquisas de natureza lexical de diversos tipos (glossários, dicionários, estudos monográficos, atlas linguísticos), desde que contemplem corpora de cunho dialetal que recubram uma área geográfica passível de cartografação digital no Tesouro.

Em síntese, três tipos de trabalhos de cunho lexical e dialetal foram utilizados como fontes de pesquisa para elaboração deste artigo: (i) produtos lexicográficos e atlas linguísticos incorporado ao TLPGP; (ii) outros atlas linguísticos publicados no Brasil e não incorporados ao TLPGP; e (iii) uma amostra de resultados de teses e dissertações originadas com base em dados lexicais documentados pelo projeto Atlas Linguístico do Brasil.

Os tesouros, do latim thesaurus, como documentos lexicográficos surgem da necessidade de armazenamento e indexação de um número considerável de dados (bigdata), razão pela qual possibilitam a manipulação de grande volume de informações registradas em documentos anteriormente dispersos e, por vezes, próprios ou específicos de certas áreas do conhecimento. Tais obras permitem uma recuperação de dados que não estariam tão acessíveis à população em geral. 
A Ciência da Computação e a implementação de diversas soluções de criação e informatização de banco de dados permitiram o avanço de produtos lexicográficos dessa natureza.

Como bem aponta Biderman (1984, p. 17), “o advento do computador constitui uma verdadeira revolução dentro da ciência da informática e da lexicografia em particular". Obras lexicográficas de valor inestimável, muitas vezes fruto do trabalho realizado por pesquisadores durante toda a sua vida, foram construídas a partir de recolha de dados, indexações e citações apontadas manualmente. A verdadeira revolução, ainda nas palavras de Biderman, é a de que

Hoje os dicionaristas não precisam mais dar o sangue para elaborarem um tesouro lexicográfico porque grande parte do trabalho manual, monótono e estafante, pode ser feito pelo computador. Além disso, os contemporâneos contam com a vantagem de produzirem uma obra mais completa e de melhor qualidade, pois economizam sua energia com a parte repetitiva do trabalho, proporcionalmente muito mais volumosa no conjunto das tarefas; dessa forma poderão utilizar essa energia para a seleção do material compilado pela máquina e para a redação do texto final, que constitui a etapa mais importante de qualquer obra lexicográfica (BIDERMAN, 1984, p. 17).

De acordo com o Manual de Tesauros monolingues, de Hagar Espanha Gomes (1990, p. 14), “O tesauro documentário surgiu da necessidade de manipular grande quantidade de documentos especializados". Tesouros dessa natureza, a depender dos seus objetivos, podem agregar dados gerais ou de domínio específico e podem ser monolíngues, bilíngues ou plurilíngues.

Um exemplo de tesouro desenvolvido no Brasil de domínio específico é o Tesouro de Folclore e Cultura Popular Brasileira ${ }^{7}$, obra que dialoga com o objeto de

${ }^{7} \mathrm{O}$ Tesouro de Folclore e Cultura Popular Brasileira é uma iniciativa do Instituto do Patrimônio Histórico e Artístico Nacional/Ministério da Cultura/Brasil. Recebeu financiamento da UNESCO para concretização da $1^{\underline{a}}$ edição. Na atualidade, é patrocinado pelo Programa Caixa de Adoção de Entidades Culturais, da Caixa Econômica Federal. Disponível em: $<$ http://www.cnfcp.gov.br/tesauro/>. Acesso em: 20 mar. 2021. 
estudo deste trabalho - brincadeiras infantis, parte da cultura imaterial brasileira e mundial.

Um exemplo de tesouro de domínio específico e bilíngue é o Tesouro do léxico patrimonial galego e português (TLPGP) desenvolvido na Galícia, com a participação de pesquisadores de Portugal e do Brasil, obra aqui eleita como fonte de dados da pesquisa, comentada na seção 1.1.

Outro tipo de documento que pode ser considerado repositório do léxico de uma língua são os atlas linguísticos. Em sua gênese, eles objetivavam dispor ou representar em mapas os resultados de uma recolha de dados in loco para proporcionar a descrição das línguas, numa perspectiva, sobretudo, diatópica.

Tomamos aqui o conceito de Atlas fornecido pela cartografia como "um conjunto de mapas ou cartas geográficas, de um conjunto de dados sobre determinado assunto, sistematicamente organizados e servindo de referência para a construção de informações de acordo com a necessidade do usuário" (TELES; RIBEIRO, 2006, p. 212).

Um atlas linguístico é essencialmente a compilação de resultados de pesquisas e apresenta vantagens de clareza e imediata percepção dos fenômenos em variação numa língua, com garantia da unidade técnica, da homogeneidade do material e da densidade de pontos estudados. Oferece para cada fenômeno uma visão espacial simultânea que permite importantes deduções de ordem histórica, geral e comparativa.

É possível observar, por meio do estudo dos atlas publicados no mundo, a evolução do método da Geografia Linguística e as áreas geográficas abrangidas pelos diversos produtos cartográficos. Ampliou-se a visão sobre espaço linguístico para além do espaço geopolítico e incorporaram-se, à cartografia, as perspectivas diageracionais, diassexuais e diastráticas, de que se ocupa a geolinguística pluridimensional. 
Ainda tratando do método da Dialetologia, convém destacar que houve uma continuada evolução ao longo dos anos de desenvolvimento da área no que se refere, por exemplo, ao estabelecimento da amplitude geográfica a considerar e às técnicas e aos fenômenos relativos à análise pré-cartográfica. Além disso, a Dialetologia tem dialogado com os avanços da Informática tanto na formação de bases de dados quanto na apresentação de amostras linguísticas.

Na seção 1.1, destacamos os aspectos atinentes ao Tesouro do léxico patrimonial galego e português (TLPGP) e aos atlas linguísticos publicados no Brasil, ainda não incorporados ao Tesouro, com ênfase nas suas características e suas soluções tecnológicas para divulgação do conhecimento sobre o léxico.

\subsection{Tesouro do léxico patrimonial galego e português - (TLPGP)}

O Tesouro do léxico patrimonial galego e português (TLPGP) é um projeto internacional e interinstitucional, celebrado entre órgãos de pesquisa galegos, portugueses e brasileiros que, juntos, desde 2009, capitaneados pela proposta integradora do Instituto da Língua Galega (ILG) da Universidade de Santiago de Compostela (USC), realizam a empreitada. Participam até o momento do Projeto 25 universidades, uma da Galícia, 21 do Brasil e três de Portugal.

O site do Tesouro contém vasta documentação relativa ao projeto interinstitucional, seus objetivos, escopo de trabalho, política de alimentação e utilização dos dados, direitos autorais, dentre outras informações ${ }^{8}$.

Interessa-nos aqui abordar o Tesouro enquanto repositório. Trata-se de uma ampla e robusta base de dados de cunho lexical e dialetal que "permite o acesso rápido e fácil à informação contida em obras sobre o léxico dialectal do galego, do português europeu e do português do Brasil” (ÁLVAREZ; 2021). As obras incorporadas ao Tesouro são organizadas segundo critérios de lematização

\footnotetext{
8 Como a exploração dessa documentação foge aos objetivos deste trabalho, sugerimos consulta direta à obra por meio do site http://ilg.usc.es/tesouro/pt.
} 
pré-definidos, englobam todas as variantes que constaram nas obras originais e, necessariamente, é indicada a localização geográfica, registrada por meio de geocódigo.

O repositório tem atualização contínua com incorporação de novos itens lexicais revelando o dinamismo que a obra tem e como se faz construir coletivamente. Em julho de 2021, o acervo digital contava com 264 obras (47 do Brasil, 128 da Galícia, 79 de Portugal, oito de Galícia e Portugal e duas de Galícia, Portugal e Brasil) que, por sua vez, somavam cerca de 284.925 registros ${ }^{9}$. O site fornece informações sobre novas incorporações em tempo real.

Para este estudo, a consulta ao Tesouro teve como ponto de partida a busca por um item lexical do galego (pita-cega) e outro do português (cabra-cega) que nomeiam "a brincadeira em que uma criança, com os olhos vendados, tenta pegar as outras".

Realizamos consultas sistemáticas ao banco de dados, seguindo os parâmetros de lematização disponíveis na base. Procedemos ao arquivamento do produto das consultas empreendidas: listagem de itens lexicais apurados armazenados em arquivos em formato pdf e em mapas salvos em formato pdf e png. Os demais passos metodológicos seguidos foram: (i) leitura dos dados; (ii) elaboração de quadro resumo contendo a listagem das obras que continham os lemas pesquisados e a respectiva área de registro das lexias (Galícia, Portugal ou Brasil), o(s) autor(es) das obras e o tipo de obra/pesquisa dialetal, como revelam o Quadro 1 (Tesouro) e o Quadro 2 (atlas linguísticos, cf. 1.2); (iii) elaboração de planilha com dados coletados no Tesouro e nos atlas considerados; e (iv) análise da amostra.

\footnotetext{
${ }_{9}^{9}$ Informação obtida no Tesouro. Disponível em: <http://ilg.usc.es/tesouro/pt/corpus.html >. Acesso em 19 jun. 2021.
} 
Quadro 1: Obras incorporadas ao Tesouro consideradas no levantamento dos dados Galícia, Portugal e Brasil

\begin{tabular}{|c|c|c|}
\hline $\begin{array}{c}\text { Área de } \\
\text { registro } \\
\text { das lexias }\end{array}$ & Autor & Tipo de obra/pesquisa dialetal \\
\hline \multirow{12}{*}{ Galícia } & $\begin{array}{l}\text { Baamonde Traveso } \\
\text { (1977) }\end{array}$ & Memória de Licenciatura \\
\hline & Babarro González (2003) & Livro \\
\hline & Bravo Criado (1984) & Memória de Licenciatura \\
\hline & Castro Castedo (1986) & Memória de Licenciatura \\
\hline & Cortés Vázquez (1954) & Livro \\
\hline & Fraiz Barreiro (1974) & Memória de Licenciatura \\
\hline & $\begin{array}{l}\text { Gómez Gallego et al. } \\
\text { (2017) }\end{array}$ & Investigação dialetológica/Banco de dados \\
\hline & $\begin{array}{l}\text { González González } \\
(2002)\end{array}$ & Tese de doutorado \\
\hline & López Taboada (1978) & Memória de Licenciatura \\
\hline & Rodríguez Lago (1974) & Memória de Licenciatura \\
\hline & Roxíos (2010) & Site internet \\
\hline & Vázquez Somoza (1986) & Memória de Licenciatura \\
\hline \multirow{6}{*}{ Portugal } & Braga (1971) & Dissertação de Licenciatura \\
\hline & Ebs Rebordosa (2020) & Investigação dialetológica/Banco de dados \\
\hline & Maia (1965) & Dissertação de Licenciatura \\
\hline & Matias (1974/1984) & Dissertação de Licenciatura \\
\hline & Medeiros (1964) & Dissertação de Licenciatura \\
\hline & Pereira (1970) & Dissertação de Licenciatura \\
\hline \multirow{6}{*}{ Brasil } & Dias (2015) & Investigação dialetológica/Banco de dados \\
\hline & Altino (2001) & Dissertação de Mestrado (Atlas Linguístico) \\
\hline & Altino (2007) & Tese de Doutorado (Atlas Linguístico) \\
\hline & Cristianini (2007) & Tese de Doutorado (Atlas Linguístico) \\
\hline & Encarnação (2010) & Tese de Doutorado (Atlas Linguístico) \\
\hline & Figueiredo Jr. (2018) & Tese de Doutorado (Atlas Linguístico) \\
\hline
\end{tabular}

Fonte: Álvarez (2021), elaborado pelas autoras

O levantamento resultou em 24 obras nas quais há registros de designativos que se aplicam ao referente pesquisado: 12 obras em galego; seis em português europeu (PE) e seis em português do Brasil (PB).

Cumpre explicitar que no Tesouro há um número considerável de atlas linguísticos brasileiros incorporados à base de dados. Alguns deles são resultados de teses de doutorado ou de dissertações de mestrado. As obras 
selecionadas como fontes para o artigo foram aquelas que continham cartas linguísticas que tratassem das denominações para a atividade lúdica aqui estudada. Ao final do artigo, listamos os trabalhos que estão na base do Tesouro e não foram utilizados no trabalho.

Por ser uma obra dinâmica, no Tesouro, a inserção de dados originados de atlas linguísticos ou de outras pesquisas de cunho dialetal ainda não está concluída, de modo que para este trabalho ampliamos a base de pesquisa com a incorporação de informações de alguns atlas linguísticos publicados no Brasil e ainda não anexados ao Tesouro, como o demonstrado em 1.2.

\subsection{Atlas linguísticos publicados no Brasil e não incorporados ao Tesouro}

Considerando aqui apenas os atlas linguísticos brasileiros já publicados que incluíram a área referente a brincadeiras infantis e nela a indagação sobre "a brincadeira em que uma criança, com os olhos vendados, tenta pegar as outras", mas que não constam do Tesouro, foram consultadas as obras a seguir contextualizadas, por data de publicação: O Esboço de um Atlas Lingüístico de Minas Gerais - EALMG (RIBEIRO et al., 1977); o Atlas Lingüístico de Mato Grosso do Sul - ALMS (OLIVEIRA, 2007); o segundo volume do Atlas LingüísticoEtnográfico da Região Sul do Brasil - ALERS (ALTENHOFEN; KLASMANN, 2011) e o Atlas Linguístico do Brasil - ALiB (CARDOSO et al., 2014).

O EALMG foi o segundo atlas publicado no Brasil ${ }^{10}$ e contou com a documentação de 116 localidades, onde se realizaram entrevistas com um ou vários informantes, em geral masculinos e de idade entre 30 e 50 anos. A Carta 38 - cabra-cega do EALMG traz um total de 117 ocorrências, assim distribuídas: cobra-cega (60), cabra-cega (29), gata-cega (23), pata-cega (03), capa-cega e pago-cego (uma ocorrência cada).

10 O primeiro atlas publicado no Brasil foi o Atlas Prévio dos Falares Baianos (ROSSI, 1963). 
O ALMS fornece, além da distribuição diatópica, também uma distribuição diassexual e diageracional, tendo sido entrevistados em cada localidade quatro informantes, dois do sexo masculino e dois do feminino, de duas faixas etárias - 18 a 30 anos e 45 a 70 anos. Na Carta QSL 0464.a - cabracega, há o registro de 100 ocorrências de denominações para a brincadeira em foco, assim distribuídas: cobra-cega (76), cabra-cega (05), gato-cego (05), cego (03), vaca-cega (02), galo-cego (02), papa-cego (02), gata-cega, cobrinha-cega, ceguinha, gabacega e bobo da corte (um registro de cada).

O ALERS é o primeiro atlas linguístico a ocupar-se de toda uma região brasileira, no caso, os três Estados do Sul: Paraná, Santa Catarina e Rio Grande do Sul. A equipe interinstitucional constituiu-se em 1987, com a participação de pesquisadores das Universidades dos três estados sob a coordenação geral de Walter Koch (UFRGS). Foram pesquisados 275 pontos na área rural e 19 na área urbana, tendo sido documentados, em geral, casais, com idade, preferencialmente, entre 28 e 58 anos.

No seu segundo volume ${ }^{11}$, o ALERS traz a Carta 306 - cabra-cega, com o registro das seguintes variantes: cobra-cega (81, com mais três, na forma diminutiva cobrinha-cega), gata-cega (76 ocorrências), pata-cega (42), gato-cego (32, a que se acrescenta uma ocorrência de gato-cega) e cabra-cega (5 ocorrências). Ocorrem, ainda, respostas não cartografadas, com menor frequência: vaca-cega (4 vezes) e ceguinho, jogo do cego, cata-cego e bruxa (uma vez cada um).

O Atlas Linguístico do Brasil - ALiB resulta de um projeto interinstitucional, iniciado em 1996, com o objetivo principal de elaboração do atlas linguístico do Brasil, no que se refere à língua portuguesa. Já com dois primeiros volumes publicados (CARDOSO et al., 2014) e outros em andamento, insere-se, metodologicamente, na linha da geolinguística pluridimensional

\footnotetext{
${ }^{11} \mathrm{O}$ primeiro volume, organizado por Koch, W.; Altenhofen, C.; Klassmann, M., foi publicado em 2002, com cartas fonéticas e morfossintáticas.
} 
contemporânea, buscando o levantamento de dados não só diatópico mas também diastrático, diageracional, diafásico e diassexual.

O corpus é constituído de dados recolhidos in loco em 250 localidades, inclusive 25 capitais de Estado ${ }^{12}$, junto a 1.100 informantes dos dois sexos, de duas faixas etárias - a primeira de 18 a 30 anos, a segunda de 50 a 65 anos - e de dois graus de escolaridade - fundamental incompleto e universitário completo - o último apenas em capitais. É coordenado por um Comitê Nacional, composto de professores/pesquisadores de nove universidades brasileiras ${ }^{13}$.

A Carta L22, (CARDOSO et al., 2014, p. 313), de autoria de Aparecida Negri Isquerdo e Anna Carolina dos Santos Ananias, intitulada "Cabra-cega denominações registradas em capitais do Brasil", traz as seguintes denominações para essa brincadeira: cabra-cega e cobra-cega, documentadas com maior frequência, em quase todas as regiões; pata-cega, em cinco capitais do Norte (Manaus, Belém, Boa Vista, Macapá e Porto Velho), uma no NE (Maranhão) e uma no Sul (Florianópolis); pega-pega, em Macapá, Teresina e Florianópolis; e gata-cega, apenas em Porto Alegre.

Como se observa por meio da Figura 1, a denominação cabra-cega está em todas as localidades pesquisadas e cobra-cega foi a forma mais produtiva nas três capitais da região Centro-Oeste (Cuiabá, Campo Grande e Goiânia), uma do Sul (Curitiba), uma do Sudeste (São Paulo), duas do Nordeste (Fortaleza e Natal); foi registrada em outras 11 capitais com graus distintos de ocorrência (Macapá, Belém, Rio Branco; Teresina, João Pessoa, Aracaju, Salvador; Belo Horizonte, Vitória, Rio de Janeiro e Porto Alegre), não tendo sido documentada em sete

${ }^{12}$ Brasília e Palmas não foram incluídas por razões metodológicas referentes às datas de fundação.

${ }^{13}$ Universidade de Brasília, Universidade Federal da Bahia, Universidade Federal do Ceará, Universidade Federal do Maranhão, Universidade Federal de Mato Grosso do Sul, Universidade Federal do Pará, Universidade Federal da Paraíba, Universidade Federal de Santa Catarina e Universidade Estadual de Londrina. 
capitais, três do Norte (Boa Vista, Manaus e Porto Velho); três do Nordeste (São Luiz, Maceió e Recife) e uma do Sul (Florianópolis).

Figura 1: CARTA L22 - Cabra-cega ${ }^{14}$ - denominações registradas em capitais do Brasil

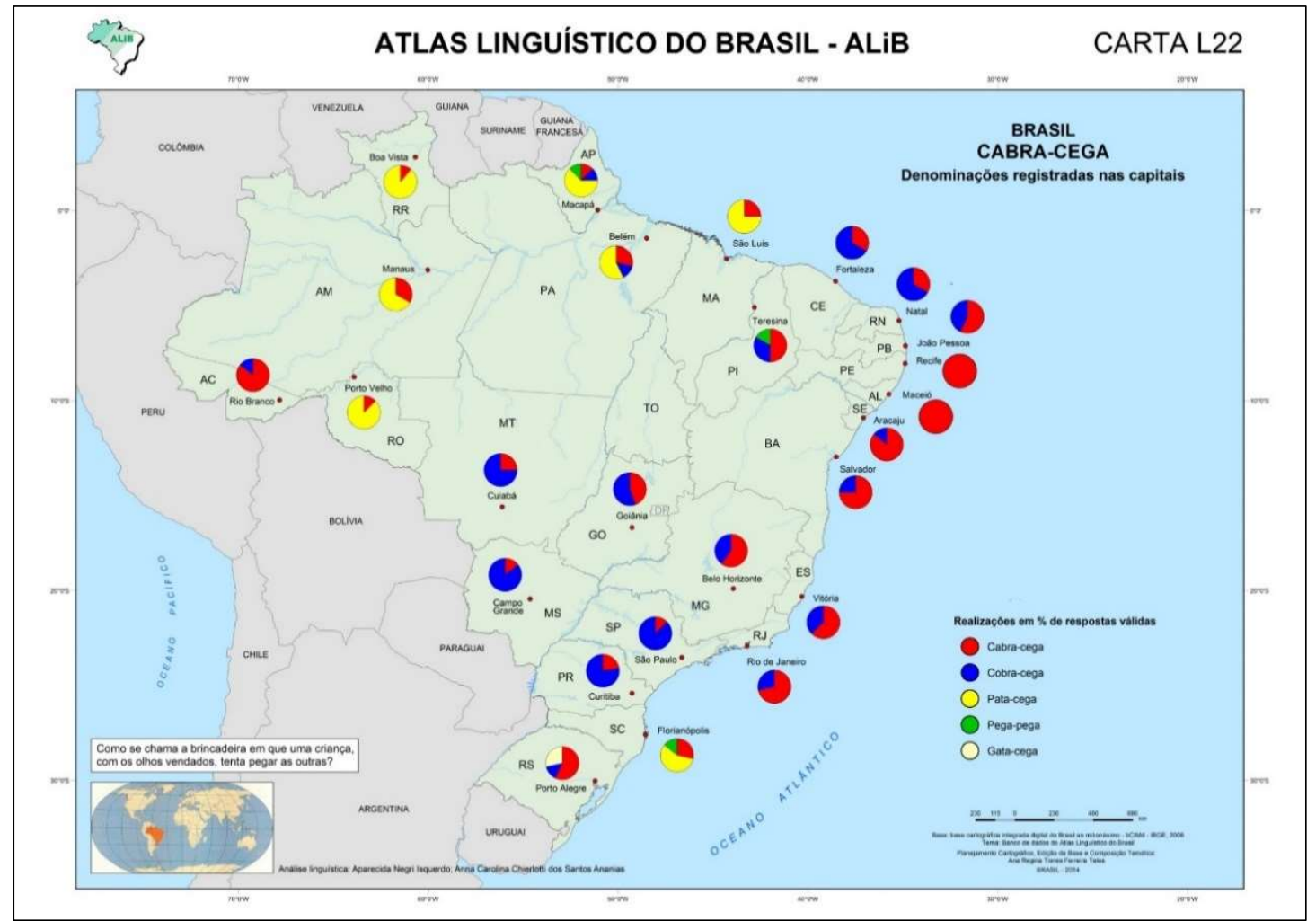

Fonte: Cardoso et al. (2014, p. 313). ${ }^{15}$

\subsection{Trabalhos de pós-graduação com dados do Projeto ALiB}

A fim de incorporamos à análise comparativa aqui empreendida os trabalhos já realizados sobre o tema, referentes ao interior do país que tomaram por base os corpora obtidos por meio do Questionário Semântico-Lexical (QLS)

\footnotetext{
${ }^{14}$ Figura 1 - Legenda da Carta L22: vermelho = cabra-cega; azul = cobra-cega; amarelo = pata-cega; verde $=$ pega-pega $;$ e amarelo claro $=$ gata-cega .

15 Em notas referentes à Carta L22, p. 312, as autoras registram como ocorrências únicas: brincadeira de pega; pega e pega-pé.
} 
do ALiB, seção destinada ao estudo dos jogos e diversões infantis (QSL 155 a 167), com 13 questões (COMITÊ NACIONAL, 2001), trouxemos os resultados das teses de doutorado de Ribeiro (2012) e de Alencar (2018), das dissertações de mestrado de Portilho (2013), de Santos (2016) e de Santos (2018) que, juntos dão conta da descrição parcial dos dados relativos a denominações da brincadeira infantil em causa, em diferentes perspectivas. Em sua maioria, as abordagens visam à descrição de áreas dialetais descritas por Nascentes (1953), de Norte a Sul, e podem ser assim organizados: Falar Amazônico, Portilho (2013); Falar Nordestino, Santos (2018); Falar Baiano, Ribeiro (2012); Falar Fluminense, Santos (2016); e parte do Falar Sulista, Alencar (2018).

Os trabalhos citados anteriormente, além de descreverem áreas dialetais, avançaram em pesquisa lexicográfica, valendo-se os autores de dicionários etimológicos, dicionários gerais de língua portuguesa contemporâneos, dicionários escolares selecionados pelo Plano Nacional do Livro Didático (PNLD) e dicionário de folclore.

Apresentamos, no Quadro 2, o elenco das obras selecionadas na categoria atlas linguísticos publicados e ainda não incorporados ao Tesouro e outros trabalhos realizados com dados de coleta para o Projeto ALiB (teses e dissertações defendidas), atinentes à temática jogos e diversões infantis. 
Quadro 2: Atlas linguísticos e trabalhos acadêmicos (teses e dissertações) considerados no levantamento dos dados - Brasil

\begin{tabular}{|l|l|}
\hline \multicolumn{1}{|c|}{ Autor } & \multicolumn{1}{c|}{ Tipo de obra /pesquisa dialetal e tema } \\
\hline Alencar (2018) & Tese de Doutorado - Jogos e diversões (São Paulo) \\
\hline Cardoso et al. (2014) & Atlas linguístico - ALiB Vol. 2 \\
\hline Altenhofen; Klassmann (2011) & Atlas linguístico - ALERS Vol. 2 \\
\hline Oliveira (2007) & Atlas linguístico - ALMS \\
\hline Portilho (2013) & $\begin{array}{l}\text { Dissertação de Mestrado - Jogos e diversões (Falar } \\
\text { Amazônico) }\end{array}$ \\
\hline Ribeiro (2012) & Tese de Doutorado - Jogos e diversões (Falar Baiano) \\
\hline Ribeiro et al. (1977) & Atlas linguístico - EALMG \\
\hline Santos (2016) & $\begin{array}{l}\text { Dissertação de Mestrado - Jogos e diversões (Falar } \\
\text { Fluminense) }\end{array}$ \\
\hline Santos (2018) & $\begin{array}{l}\text { Dissertação de Mestrado - Jogos e diversões (Falar } \\
\text { Nordestino) }\end{array}$ \\
\hline
\end{tabular}

Fonte: Elaborado pelas autoras.

Em resumo, para este estudo, contamos com 33 obras, sendo: 24 do acervo do Tesouro (cf. Quadro 1), quatro atlas linguísticos publicados no Brasil e cinco trabalhos de pós-graduação produzidos com dados do Projeto ALiB, não incorporados ao Tesouro (cf. Quadro 2).

\section{TIRANDO A VENDA DOS OLHOS: DESCRIÇÃO LINGUÍSTICA E HIPÓTESES INTERPRETATIVAS}

Na seção dois, objetivando deixar o texto mais didático, optamos por subdividir a análise em dois itens: (i) descrição linguística; e (ii) hipóteses interpretativas.

\subsection{Descrição linguística}

A atividade lúdica que serve de base para a coleta empreendida na pesquisa para este artigo se caracteriza pela presença de crianças em círculo ou não, havendo dentre elas uma que está com os olhos vendados e deve tentar pegar as outras. A criança que está com os olhos vendados, em geral, é 
reconhecida pelo designativo que dá nome à brincadeira (cabra-cega, em português, ou pita-cega, em galego, por exemplo). Quem for pego pelo brincante que está com os olhos vendados passará a ter os seus olhos vendados e será o próximo a tentar pegar um dos demais participantes.

Há descrições da execução da brincadeira que contemplam a fase de rodar "a caba-cega" para que fique "tonta" ou "desnorteada" e não localize os componentes da atividade de imediato. Cantam-se músicas de roda ou recitamse parlendas, como a seguir apresentada: “- Cabra-cega, de onde vens? / - Do moinho. / - Que trazes? / - Pão e vinho. / - Me dá um pouquinho? / - Não. / Gulosa, gulosa" (FRIEDMANN, 2014, p. 32).

No Tesouro, há o registro da seguinte ocorrência de parlenda: “O informante lembra un recitado en castelán: Pita ciègha ¿de dónde viènes? / Vengo de Castilla. I ¿Qué traes para comer? / Pan y vino. (O recitado continúa pero o enquisado non recorda como segue)" (ÁLVAREZ, 2021, grifo no original).

A brincadeira é conhecida desde a antiguidade clássica e, sabidamente, difundida em todo o mundo. Pesquisas indicam que a atividade lúdica era praticada por adultos, uma típica diversão palaciana e importante passatempo dos membros da corte. Atesta-se tal prática a partir das obras de arte que se encontram expostas em diversos museus do mundo e que retratam o convívio dos nobres e o desejo de ver exibidos em pintura ou tapeçarias o seu cotidiano. Conforme Ariès (1986, p. 93), "numa tapeçaria do início do século XVI alguns camponeses e fidalgos, estes últimos mais ou menos vestidos de pastores, brincam de uma espécie de cabra-cega: não aparecem crianças". A informação de que não há crianças confirma a prática da atividade por adultos.

De acordo com Ribeiro (2012, p. 300), “Vários pintores europeus retrataram o jogo e sua associação com cenas de conquistas amorosas dos adultos, singelamente encobertas durante a brincadeira". A autora destaca que Lhotê (1996), em seu Dictionnaire des jeux de société, traz uma descrição do jogo 
anotada em 1824, onde se lê: “[...] tão cego como o amor, nada pode ser discernido, ele é colocado no centro de um círculo e deve reconhecer a pessoa que ele tocou [...]." (LHOTÊ, 1996, p. 135, tradução nossa) ${ }^{16}$.

No latim registram-se musca caeca (mosca-cega) ou gallina aenea (galinha de bronze $)^{17}$ como designativos para a brincadeira praticada em Roma. É nomeada em algumas línguas românicas como cabra-cega (português), pita-cega (galego), colin-maillard (francês), gallina-ciega (espanhol), mosca-cieca (italiano) e em germânicas, como blinde Kuh (em alemão "blind" - cego/ "Kuh" - vaca, "vacacega") e blindman's buff (inglês).

Sabe-se que o entretenimento infantil é extremamente comum, sendo ainda praticado na atualidade, embora, culturalmente, por força da significativa queda da prática de realizar brincadeiras ao ar livre e nas ruas, credita-se a permanência e a realização desse tipo de brincadeira de "correr e pegar" à escola, local onde, majoritariamente, se registra a execução dessa atividade pedagógica e de entretenimento. Na escola, a "cabra-cega" atende a uma necessidade de desenvolvimento de alguns dos cinco sentidos que o ser humano possui: visão, tato e algumas vezes audição (caso esteja sendo praticada a versão com o uso de parlendas vistas anteriormente).

${ }^{16}$ No original: [...] aussi aveugle que l'Amour, ne peut rien discerner, il est placé au centre d'un cercle et doit reconnaître la personne qu'il parvient à toucher.[...].

17 LATIM (Thesaurus iuris romani (1744). Disponível em: $<$ https://play.google.com/books/reader?id=CT1s9CuG3ckC\&hl=pt\&pg=GBS.PA1523>. Acesso em: 24 mar. 2021); GALEGO (Tesouro do léxico patrimonial galego português. Disponível em: $<$ http://ilg.usc.es/tesouro/pt/search\#search=normal\&mode=lema\&q=pita+cega $>$. Acesso em: 20 mar. 2021); FRANCÊS (Dictionnaire Le Robert. Disponível em: $<$ https://dictionnaire.lerobert.com/definition/colin-maillard.> Acesso em: 20 mar 2021); ESPANHOL (Diccionario de la lengua española. Disponível em: $<$ https://dle.rae.es/gallo\#9Fm6Ljh>. Acesso em: 20 mar. 2021); ITALIANO (Dicionário de italiano editado pelo Instituto Treccani. Disponível em: $<$ https://www.treccani.it/vocabolario/mosca/>. Acesso em: 20 mar. 2021); ALEMÃO (Dicionário PONS. Disponível em: <https://de.pons.com/\%C3\%BCbersetzung/deutschportugiesisch/blinde+kuh?bidir=1>. Acesso em: 20 mar. 2021) e INGLÊS (Dicionário Collins. Disponível em: <https://www.collinsdictionary.com/pt/dictionary/english/blindmans-buff>. Acesso em: 20 mar. 2021). 
Tomando os dados originados das 33 obras nas quais há registro de denominações dessa brincadeira e considerando os objetivos da análise e o escopo do trabalho, selecionamos aquelas que preenchiam um dos seguintes critérios: (i) conter um zoomorfismo (elemento motivador recorrente em várias línguas); (ii) conter a unidade léxica "cego" (associação com o sentido humano da visão reforçado na brincadeira); ou (iii) conter a unidade léxica "pegar" (associação com o sentido humano do tato reforçado na brincadeira) ${ }^{18}$.

Elaboramos o Quadro 3, que reúne 25 agrupamentos, alguns deles como denominações recorrentes e sem variação e outros reunidos por conter o formante "pegar" (com seis denominações); o formante "cego/cega/ceguinho" (com seis denominações); ou variações masculino/feminino ("galo/galinha"; "gato/gata"). Há lexias distintas e/ou agrupamentos assim considerados: (i) duas em galego; (ii) quatro em português europeu; e (iii) 26 em português brasileiro ${ }^{19}$.

A leitura do Quadro 3 permite verificar que, como sinalizado em destaque, cabra-cega e pata-cega ocorrem nas duas variedades do português aqui consideradas (PB e PE); pita-cega e galinha-cega ocorrem em galego e em português europeu, às quais agregamos a lexia galo-cego, com única ocorrência no português brasileiro.

${ }_{18}$ Alguns dados levantados em trabalhos de pós-graduação (teses e dissertações) e em atlas linguísticos fotografaram um conjunto de denominações que foram de ocorrência única, não atendem a um dos três critérios anteriormente descritos e não estão contempladas neste estudo. São elas: esconde-esconde e gato-mia (ALENCAR, 2018); bombarquim, bitica, cabo-soldado, se esconder, doidinho, cara-preta (SANTOS, 2018); combater (SANTOS, 2016); adivinha, brincadeira do esconderijo, cara-preta, combater; múmia e percula (RIBEIRO, 2012); bruxa (KLASSMANN; ALTENHOFEN (2011); bobo da corte (OLIVEIRA, 2007).

${ }^{19}$ De acordo com o Tesouro, há um registro de pira-mãe na obra de Dias (2015). A descrição trazida não corresponde à brincadeira aqui considerada. No Tesouro temos: "pira mãe [.pira'mãj] s.f Uma brincadeira em que uma criança corre atrás das outras para tocar numa delas, antes que alcance um ponto combinado? Dias P 2015. lema: cabra-cega sf.". 
Quadro 3: Denominações para a "brincadeira de pegar com olhos vendados" em galego (GA), português europeu (PE) e português brasileiro (PB)

\begin{tabular}{|c|c|c|}
\hline $\begin{array}{c}\text { Itens lexicais e } \\
\left.\text { (n.o obras com registros }{ }^{20}\right)\end{array}$ & Língua & Fonte \\
\hline barata-tonta (1) & PB & Portilho (2013) \\
\hline cabra-cega / cabra-ciega (3) & PE & $\begin{array}{l}\text { Ebs Rebordosa (2020); Matias (1974/1984); } \\
\text { Pereira (1970) }\end{array}$ \\
\hline cabra-cega (14) & PB & $\begin{array}{l}\text { Alencar (2018); Altenhofen; Klassmann } \\
\text { (2011); Altino (2007); Cardoso et al. } \\
\text { (2014); Cristianini (2007); Dias (2015); } \\
\text { Encarnação (2010); Figueiredo Jr. (2018); } \\
\text { Oliveira (2007); Portilho (2013); Ribeiro } \\
\text { (2012); Ribeiro et al. (1977); Santos (2016); } \\
\text { Santos (2018) }\end{array}$ \\
\hline cata-cega (1) & $\mathrm{PB}$ & Altenhofen; Klassmann (2011) \\
\hline capa-cega / capa-cego (2) & PB & $\begin{array}{l}\text { Ribeiro et al. (1977) } \rightarrow \text { capa-cega; } \\
\text { Alencar }(2018) \rightarrow \text { capa-cego }\end{array}$ \\
\hline $\begin{array}{l}\text { cego / ceguinho/ ceguinha / } \\
\text { brincadeira do cego / brincar de } \\
\text { ceguinho/ brincar do ceguinho (5) }\end{array}$ & PB & $\begin{array}{l}\text { Altenhofen; Klassmann (2011); Oliveira } \\
\text { (2007); Ribeiro (2012); Santos (2016); } \\
\text { Santos (2018). }\end{array}$ \\
\hline cobra (1) & $\mathrm{PB}$ & Ribeiro (2012) \\
\hline cobra-cega / cobrinha-cega (14) & PB & $\begin{array}{l}\text { Alencar (2018); Altenhofen; Klassmann } \\
\text { (2011); Altino (2001); Altino (2007); } \\
\text { Cardoso et al. (2014); Cristianini (2007); } \\
\text { Encarnação (2010); Figueiredo Jr. (2018); } \\
\text { Oliveira (2007); Portilho (2013); Ribeiro } \\
\text { (2012); Ribeiro et al. (1977); Santos (2016); } \\
\text { Santos (2018). }\end{array}$ \\
\hline cobra-morta (1) & $\mathrm{PB}$ & Santos (2016) \\
\hline gaba-cega (1) & PB & Oliveira (2007) \\
\hline $\begin{array}{l}\text { galiña-cega / gallinita-ciega / } \\
\text { gallina-ciega (6) }\end{array}$ & GA & $\begin{array}{l}\text { Gómez (2017); Rodríguez (1974); } \\
\text { Baamonde (1977); Cortés (1954); Fraiz } \\
\text { Barreiro (1974); López Taboada (1978) }\end{array}$ \\
\hline galinha-cega (1) & PE & Matias $(1974 / 1984)$ \\
\hline galo-cego (1) & PB & Oliveira (2007) \\
\hline $\begin{array}{l}\text { gata-cega / gato-cego / gato-cega } \\
\text { (9) }\end{array}$ & PB & $\begin{array}{l}\text { Alencar (2018); Altenhofen; Klassmann } \\
\text { (2011); Altino (2007); Cardoso et al. } \\
\text { (2014); Figueiredo Jr. (2018); Oliveira } \\
\text { (2007); Ribeiro (2011); Ribeiro et al. (1977); } \\
\text { Santos (2016) }\end{array}$ \\
\hline jogo do cego (1) & PB & Altenhofen; Klassmann (2011) \\
\hline mãe-cega (1) & PB & Altino (2001) \\
\hline
\end{tabular}

${ }^{20}$ Computados os registros apenas uma vez para cada obra. 


\begin{tabular}{|c|c|c|}
\hline Maria-cega (2) & PB & Alencar (2018); Santos (2018). \\
\hline nó-cego / brincar de nó-cego (2) & $\mathrm{PB}$ & Portilho (2013); Ribeiro (2012) \\
\hline pago-cego (1) & PB & Ribeiro et al. (1977) \\
\hline papa-cega (1) & PB & Oliveira (2007) \\
\hline pata-cega (2) & $\mathrm{PE}$ & Maia (1965); Medeiros (1964) \\
\hline pata-cega (9) & PB & $\begin{array}{l}\text { Altenhofen; Klassmann (2011); Cardoso } \\
\text { et al. (2014); Dias (2015); Figueiredo Jr. } \\
\text { (2018); Oliveira (2007); Portilho (2013); } \\
\text { Ribeiro (2012); Ribeiro et al. (1977); Santos } \\
\text { (2018) }\end{array}$ \\
\hline pata-choca (1) & PB & Portilho (2013) \\
\hline $\begin{array}{l}\text { pega / brincadeira de pega / pega- } \\
\text { pega / pega-pé / } \\
\text { mãe pega-pega } \\
\text { pira-pega (11) }\end{array}$ & PB & $\begin{array}{l}\text { Alencar (2018); Altenhofen; Klassmann } \\
\text { (2011); Cardoso et al. (2014); Dias (2015); } \\
\text { Encarnação (2010); Figueiredo Jr. (2018); } \\
\text { Oliveira (2007); Portilho (2013); Ribeiro } \\
\text { (2012); Santos (2016); Santos (2018). }\end{array}$ \\
\hline pira-cega (1) & PB & Portilho (2013) \\
\hline pita-cega (12) & GA & $\begin{array}{l}\text { Baamonde Traveso (1977); Babarro } \\
\text { González (2003); Bravo Criado (1984); } \\
\text { Castro Castedo (1986); Cortés Vázquez } \\
\text { (1954); Fraiz Barreiro (1974); Gómez } \\
\text { Gallego (2017); González González } \\
\text { (2002); López Taboada (1978); Rodríguez } \\
\text { Lago (1974); Roxíos (2010); Vázquez } \\
\text { Somoza (1986) }\end{array}$ \\
\hline pita-cega (1) & PE & Braga (1971) \\
\hline quebra-cega (1) & $\mathrm{PB}$ & Ribeiro (2012) \\
\hline tapa-cego (1) & $\mathrm{PB}$ & Santos (1916) \\
\hline vaca-cega (4) & $\mathrm{PB}$ & $\begin{array}{l}\text { Altenhofen; Klassmann (2011); Altino } \\
\text { (2007); Oliveira (2007); Ribeiro (2012) }\end{array}$ \\
\hline
\end{tabular}

Fonte: Elaborado pelas autoras, com base nas obras indicadas no quadro.

\subsection{Hipóteses interpretativas}

A análise, na perspectiva da sua motivação, mostra a predominância de formas lexicais formadas por um zoônimo, seguido de um adjetivo descritivo, no caso, "cego/cega"21. Como revelam os dados, a motivação "cego/cega" está

${ }^{21}$ Embora não façam parte do corpus aqui analisado (português europeu, português brasileiro e galego), merece registro que outras duas línguas românicas (espanhol-galinha-ciega - e italiano 
presente em 20 das variantes lexicais documentadas, dentre elas oito estão com função qualificativa do nome de um animal.

A prática de utilizar nomes de animais para denominar referentes da realidade é recorrente, particularmente na língua falada (ALINEI, 1983). Nos casos aqui analisados, na denominação da atividade lúdica, ocorre a associação entre o nome de um animal e o adjetivo "cego/cega" para nomear o tipo de brincadeira em que um dos participantes fica com os "olhos vendados", ou seja, evoca-se o sema básico da definição da unidade léxica cego "privado da visão; organicamente incapaz de ver" (AULETE, 2006) e, por um processo de analogia com uma das características da brincadeira (olhos vendados que privam a criança da função da visão), nomeia-se a atividade lúdica.

No caso, no processo de nomeação da brincadeira são tomados nomes de animais como cabra, cobra, gato, galo, galinha, vaca, tipos comuns ao meio rural, independentemente da amplitude e da localização geográfica. Trata-se do processo do zoomorfismo muito recorrente na literatura para a caracterização de personagens, a par do antropomorfismo, também frequente na nomeação de referentes da realidade. O zoomorfismo configura-se, pois, como um traço semântico, nos moldes de Pottier (1978) que, no âmbito deste estudo, é recorrente nos nomes da brincadeira infantil em causa.

Nesse processo, a relação entre os formantes das unidades léxicas ora é mais opaca ora mais transparente. À exceção de "cobra", os animais cujos nomes são associados ao adjetivo "cego" não se enquadram entre os nocivos e ferozes; ao contrário, são tipos comuns no meio rural e de amigável convivência com os humanos, em graus distintos de proximidade, cada um com sua importância na realidade cotidiana do ser humano, seja como subsistência, seja como fonte motivadora de histórias que permeiam o folclore popular, incluindo brincadeiras

- mosca-cieca) e uma língua germânica (alemão - blind Kuh - "vaca-cega" em português) seguem o mesmo padrão formativo nas denominações para a brincadeira aqui descrita. 
e parlendas, na esfera do lúdico. Conforme o Quadro 4, animais pertencentes a quatro classes figuram nas denominações da brincadeira: mamíferos (cabra, gato, vaca); aves (galo/galinha, pata, pita); inseto (barata) e anfíbio (cobracega $)^{22}$, conforme atesta a amostra de exemplos listados.

Quadro 4: Zoomorfismos na nomeação da “brincadeira de pegar com olhos vendados" - natureza dos animais

\begin{tabular}{|c|c|}
\hline Tipo de animal & Denominação \\
\hline Mamífero & cabra-cega, vaca-cega, gato-cego/gata-cega \\
\hline Ave & galo-cego, galinha-cega, pata-cega/pata-choca, pita-cega \\
\hline Anfíbio & cobra/cobra-cega/cobrinha-cega/cobra-morta \\
\hline Inseto & barata-tonta \\
\hline
\end{tabular}

Fonte: Elaborado pelas autoras.

Como visto na seção 1.2, os resultados discutidos e explicitados por meio da Figura 1 (CARTA L22 - Cabra-cega), o uso da denominação cobra-cega para a brincadeira em pauta em $72 \%$ das capitais brasileiras, ou seja, em 18 das 25 investigadas pelo $\mathrm{ALiB}$, demonstra que essa lexia representa a norma lexical do português do Brasil. Está registrada em Houaiss (2001) como forma parônima de cabra-cega, forma documentada nas 25 capitais brasileiras, também com graus distintos de ocorrência. Câmara Cascudo (1972), no verbete cobra-cega, faz remissão para cabra-cega.

Em se tratando de motivação, qual seria a causa do uso do termo cobracega, tomado da Biologia, para nomear a brincadeira? Duas possibilidades de análise avultam: 1) uma alteração fonética da forma lexical cabra-cega transplantada pelo colonizador que se disseminou por todas as regiões brasileiras; 2) uma unidade lexical decorrente, inicialmente, de um processo de

\footnotetext{
${ }^{22}$ As cobras-cegas, ou cecílias, ao contrário dos demais tipos de cobras que pertencem à classe dos répteis, no âmbito da Biologia, pertencem à classe dos anfíbios (gimnofionos) em decorrência das características do animal (corpo comprido, alongado e sem patas, tal como as serpentes).
} 
neologismo semântico em que o nome de cobra passou a nomear um tipo de brincadeira, seguindo a tendência de zoomorfização tão peculiar no processo de nomeação de determinados referentes que evocam aspectos da cultura regional.

No caso, não pode ser desconsiderada uma possível analogia entre características da brincadeira e alguns traços que individualizam o anfíbio "cobra-cega", espécie comum no Brasil: olhos tão discretos que carecem de atenção para serem identificados, por isso tem-se a impressão de que esse tipo de animal é completamente cego, por aparentemente não possuir essa estrutura. Assim, a rapidez de movimento desse tipo de anfíbio, associada à sua aparente cegueira, somada ao fato de ser essa cobra um tipo comum não só no meio rural mas também no meio urbano onde ainda há a presença de serapilheira ${ }^{23} \mathrm{em}$ terrenos baldios pode ter sido associada às características da brincadeira de "pegar com olhos vendados".

No exame da motivação de um item lexical é pertinente considerar o princípio de que "as etimologias populares são conceitos motivados, e por isso mesmo podem dar lugar a realidades folclóricas" (BALDINGER, 1966, p. 53) e que as características do meio ambiente exercem influência na língua, neste caso nas escolhas lexicais, quando fatores sociais incidirem sobre ele (SAPIR, 1961).

A motivação do signo é abordada por Alinei (1984), cuja teoria focaliza, fundamentalmente, a questão da motivação no processo de nomeação dos elementos da realidade. Esse autor parte do princípio de que todo signo é motivado no momento de sua criação. Em vista disso, admite dois tipos de estrutura do significado: a genética e a funcional. A primeira corresponde à estrutura triádica e a segunda, à estrutura dual. Alinei (1984) entende que na análise da estrutura do conceito de significado deve-se considerá-lo no momento de sua criação, pois, segundo ele, na sua origem, todo signo é motivado uma vez

23 "Bras. Camada que recobre o solo de florestas e bosques, feita de folhas, ramos etc. em decomposição misturados a terra" (AULETE, 2006). 
que o denominador no ato de denominação de um novo referente, na maioria das vezes, busca no próprio sistema da língua elementos para subsidiar a criação do novo item lexical. Todavia, após criada, a palavra adquire a sua funcionalidade, tornando-se assim, gradativamente, arbitrária, perdendo paulatinamente a sua motivação inicial. Assim, "partindo de um novo referente, estuda-se a modalidade da formação de um neologismo, ou do desenvolvimento semântico de uma palavra já existente"24 (ALINEI, 1984, p. 16, tradução nossa).

Ainda segundo esse semanticista, no processo de nomeação, a motivação é necessária porque é baseada em palavras pré-existentes já conhecidas pelos falantes. Por meio da "reciclagem" de velhas palavras, o falante coloca "marcas" (trade-marking) nas novas criações e a vantagem desse recurso é a de que se pode criar algo novo sem ter tido algo novo em nossas mãos: que é a essência da "recycling" (ALINEI, 1980).

Nessa perspectiva, pode-se considerar que, no processo de nomeação da brincadeira de correr e pegar, as diferentes denominações, à medida que são formadas por unidades lexicais que nomeiam outros referentes do mundo real, foram "recicladas" pelo falante para denominar a brincadeira.

No corpus aqui estudado, das 25 denominações distintas ou agrupadas, 20 contêm a unidade léxica "cego/cega"; quatro contêm um zoônimo e uma, contabilizada em um único agrupamento, contém a unidade léxica "pegar", estas últimas focalizadas na sequência.

Sendo a "cabra-cega" uma brincadeira de correr e pegar, na qual se estimula o desenvolvimento do tato (um dos cinco sentidos humanos), é natural que um ou mais de um dos designativos utilizados para nomear a brincadeira tenham sido motivados pelo "ato de pegar". Os seis registros de denominações formadas com o item lexical "pegar", associada a outras unidades léxicas,

\footnotetext{
${ }^{24}$ No original: ".. partendo da un nuovo referente, si studiano le modalità della formazione di un neologismo, o dello sviluppo semantico di una parola già esistente".
} 
ocorrem no português do Brasil, em casos de construções como: brincadeira de pega, mãe pega-pega, pega, pega-pega, pega-pé e pira-pega.

Excluindo-se as lexias com o formante "pegar", chegamos ao Quadro 5, com um total de 24 denominações (algumas em agrupamentos), reunidas segundo quatro combinações em termos estruturais.

Quadro 5: Denominações para a brincadeira de "pegar com olhos vendados" zoomorfismos e formante cego/cega

\begin{tabular}{|c|c|c|c|}
\hline ZOÔNIMO & $\begin{array}{c}\text { ZOÔNIMO + } \\
\text { LEXIA } \neq \text { DE } \\
\text { CEGO/CEGA }\end{array}$ & $\begin{array}{c}\text { NÃO ZOÔNIMO + } \\
\text { CEGO/CEGA }\end{array}$ & $\begin{array}{l}\text { ZOÔNIMO + } \\
\text { CEGO/CEGA }\end{array}$ \\
\hline - cobra & $\begin{array}{l}\text { - barata-tonta } \\
\text { - cobra-morta } \\
\text { - pata-choca }\end{array}$ & $\begin{array}{l}\text { - cata-cego } \\
\text { - capa-cega / capa-cego } \\
\text { - brincadeira do cego / } \\
\text { brincar do/ de ceguinho } \\
\text { - gaba-cega } \\
\text { - jogo do cego } \\
\text { - mãe-cega } \\
\text { - Maria-cega } \\
\text { - nó-cego / brincar de } \\
\text { nó-cego } \\
\text { - pago-cego } \\
\text { - papa-cega } \\
\text { - pira-cega } \\
\text { - quebra-cega } \\
\text { - tapa-cego }\end{array}$ & $\begin{array}{l}\text { - cabra-cega / cabra-ciega } \\
\text { - cobra-cega / cobrinha-cega } \\
\text { - galiña-cega / gallinita- } \\
\text { ciega / gallina-ciega; } \\
\text { galinha-cega / galo-cego } \\
\text { - gata-cega/gato-cego/ } \\
\text { gato-cega } \\
\text { - pata-cega } \\
\text { - pita-cega } \\
\text { - vaca-cega }\end{array}$ \\
\hline
\end{tabular}

Fonte: Elaborado pelas autoras.

O quadro mostra que, numa gradação, temos: (i) uma lexia de natureza zoonímica; (ii) três lexias formadas por um zoônimo associado a itens lexicais diferentes de "cego/cega"; (iii) 13 lexias que reúnem um formante sem motivação zoonímica à unidade léxica "cego/cega"; e (iv) sete lexias cuja estrutura revela a presença de um zoônimo associado à forma léxica "cego/cega". 


\section{VAMOS CONTINUAR A BRINCADEIRA? BREVES CONSIDERAÇÕES FINAIS}

Este artigo teve como propósito analisar as denominações em galego e em português (PB e PE) para "a brincadeira em que uma criança, com os olhos vendados, tenta pegar as outras", com base em dados extraídos do Tesouro do léxico patrimonial galego e português, de cinco atlas linguísticos - EALMG (RIBEIRO et al., 1977); ALMS (OLIVEIRA, 2007); ALERS (ALTENHOFEN; KLASMANN, 2011) e ALiB (CARDOSO et al., 2014) - e de cinco trabalhos de pós-graduação (mestrado e doutorado) ${ }^{25}$. O corpus aqui estudado reuniu 32 denominações distintas - duas em galego; quatro em português europeu e 26 em português brasileiro. Desse acervo vocabular, 20 são unidades formadas com a unidade léxica "cego/cega" com função qualificativa, associada a um nome. A mesma brincadeira também foi nomeada com itens lexicais compostos com o verbo "pegar", seis ao todo: brincadeira de pega, mãe pega-pega, pega, pega-pega, pega-pé e pira-pega.

Há que se considerar ainda que, das 20 denominações formadas com a unidade léxica cego/cega, em sete se manifesta o fenômeno do zoomorfismo (cabracega; cobra-cega; galinha-cega /galo-cego; gato-cego/gata-cega; pita-cega; pata-cega; vacacega) e 13 revelam-se com unidades formadas por lexias distintas e sem um elemento léxico de motivação agregadora, como visto no Quadro 5 (cata-cego, capa-cega/capa-cego, brincadeira do cego, jogo do cego, mãe-cega, Maria-cega, papa-cega, dentre outras).

Há outros casos de zoomorfismo nos quais não se registrou a unidade léxica "cego/cega" com função qualificativa, a saber: cobra, barata-tonta, cobramorta e pata-choca.

Do ponto de vista da motivação, notamos que as denominações

${ }^{25} \mathrm{Cf}$. item 1.3 deste trabalho. 
mencionadas ao longo deste texto apontam para a valorização do ambiente rural na nomeação da brincadeira, na medida em que são formadas por meio da associação entre itens lexicais que evocam esse ambiente, aqui representado por zoônimos de diferentes espécies, e o adjetivo cego/cega que, nas novas formações, se cristalizou para nomear outro referente, no caso um tipo de brincadeira infantil. Processo similar pode ser observado com as composições com o verbo pegar, cujo fio norteador na formação dos nomes da brincadeira foram motivações de outra natureza: o tato materializado pelo ato de "pegar".

O estudo evidenciou a importância da criação e manutenção de grandes bases lexicais como fonte de pesquisa, a exemplo do TLPGP - Tesouro Léxico Patrimonial Galego Português (ÁLVAREZ, 2021), uma das fontes para este estudo.

Destacamos também que os atlas linguísticos seguem fornecendo dados primários para a alimentação de grandes bases de dados digitais, a exemplo do Tesouro que reúne amostras originadas de diferentes fontes de cunho dialetal (atlas linguísticos, trabalhos monográficos a partir de dados geolinguísticos, glossários, vocabulários produzidos com base em dados dialetais).

Embora esta proposta não tenha tido como objetivo a realização de estudo de caráter histórico, constatamos que o acesso ao TLPGP, obra que incorporou léxicos produzidos em diferentes sincronias da história da língua como fontes para pesquisas de caráter linguístico e historiográfico, pode permitir a análise da natureza linguística e das motivações semânticas identificadas na forma de nomear em línguas diversas de uma mesma família ou não, veiculadas em diferentes espaços e em épocas distintas. Estudos com dados de outra área semântica poderão ratificar o exposto ou apontar outras perspectivas de análise. 


\section{REFERÊNCIAS}

ALENCAR, Beatriz Aparecida. O léxico de brinquedos e brincadeiras infantis no estado de São Paulo, 2018, 575 f. Tese (Doutorado em Letras) Universidade Federal de Mato Grosso do Sul, Três Lagoas, 2018.

ALINEI, Mário. Le due strutture del significato. In: ALINEI, Mário. Lingua e dialetti: struttura, storia e geografia. Bologna: Ed. II Mulino, 1984. p. 13-21.

ALINEI, Mário. The structure of meaning revisited. Quaderni di Semantica. Bologna, Anno I, n. 2, p. 289-305, 1980.

ALINEI, Mario. "Arc-en-ciel ". In: Atlas Linguarum Europae. Assen-Maastricht: Van Gorcum, I, 1983. Volume I - Commentaires.

ALTENHOFEN, Cléo Vilson; KLASSMANN, Mário Silfredo (org). Atlas LinguísticoEtnográfico da Região Sul do Brasil. v. 2. Porto Alegre: Ed. da UFRGS; Florianópolis, Ed. da UFSC, 2011.

ÁLVAREZ, Rosario (coord.). Tesouro do léxico patrimonial galego e portugués. Santiago de Compostela: Instituto da Língua Galega. Disponível em: [http://ilg.usc.es/tesouro/]. Acesso em: 20 mar. 2021.

ARIÈS, Philippe. História social da criança e da família. 2. ed. Rio de Janeiro: LTC, 1986.

AULETE, Francisco J. Caldas; VALENTE, Antonio Lopes dos Santos. Aulete digital: Dicionário Contemporâneo de Língua Portuguesa. Rio de Janeiro: Lexikon Editora Digital, 2006. Disponível em: [http://aulete.com.br/]. Acesso em: 20 mar.2021

BALDINGER, Kurt. Língua e cultura. ALFA. Revista de Linguística. São Paulo, v. 9, p. 37-56, 1966.

BIDERMAN, Maria Tereza Camargo. A ciência da lexicografia. Alfa, São Paulo, n. 28 (supl.), p. 1-26, 1984.

CÂMARA CASCUDO, Luís da. Dicionário do Folclore Brasileiro. São Paulo: Tecnoprint, 1972. Coleção Prestígio/Ediouro.

CARDOSO, Suzana et al. Atlas Linguístico do Brasil. Londrina: Eduel, 2014.2 v.

COMITÊ NACIONAL DO PROJETO ALiB. Atlas Linguístico do Brasil: questionários 2001. Londrina: Eduel, 2001.

FRIEDMANN, Adriana. A arte de brincar: brincadeiras e jogos tradicionais. 10.ed. Petrópolis: Vozes, 2014.

GOMES, Hagar Espanha. Manual de elaboração de tesauros monolingues. MEC/SESU/ Programa Nacional de Bibliotecas das Instituições de Ensino Superior/CAPES/MCT. Ministério da Ciência e Tecnologia, CNPq. Brasília, 1990. Disponível em: [http://www.dominiopublico.gov.br/download/texto/me002423.pdf]. Acesso em: 20 mar. 2021.

HOUAISS, Antonio. Dicionário Houaiss da Língua Portuguesa. Rio de Janeiro: Editora Objetiva, 2001. 
KOCH, Walter.; ALTENHOFEN, Cléo V.; KLASSMANN, Mário S. (orgs). Atlas Linguístico-Etnográfico da Região Sul do Brasil. v. 1. Porto Alegre: Ed. da UFRGS; Florianópolis: Ed. da UFSC, 2002.

LHOTÊ, Jean-Marie. Dictionnaire des jeux de siciété. Flammarion: Paris, 1996.

NASCENTES, Antenor. O linguajar carioca. 2. ed. Completamente refundida. Rio de Janeiro: Organização Simões, 1953.

OLIVEIRA, Dercir Pedro de (org.) Atlas Lingüístico de Mato Grosso do Sul. Campo Grande: Ed. da UFMS, 2007.

PORTILHO, Danyelle Almeida Saraiva. O falar amazônico: uma análise da proposta de Nascentes (1953) a partir de dados do Projeto $A L i B, 2013$, 155f. Dissertação (Mestrado em Estudos de Linguagens) - Universidade Federal do Mato Grosso do Sul, Campo Grande, 2013.

POTTIER, Bernard. Linguística geral: teoria e descrição. Rio de Janeiro: Presença: Ed. da Universidade Santa Úrsula, 1978.

RIBEIRO, José et al. Esboço de um atlas linguístico de Minas Gerais. Rio de Janeiro: Casa de Rui Barbosa, 1977.

RIBEIRO, Silvana Soares Costa. Brinquedos e brincadeiras infantis na área do Falar Baiano, 2012, 3v. 752f. Tese (Doutorado em Letras) Universidade Federal da Bahia, Salvador, 2012.

ROSSI, Nelson. Atlas Prévio dos Falares Baianos. Rio de Janeiro: Ministério de Educação e Cultura / Instituto Nacional do Livro, 1963.

SANTOS, Graziele Ferreira da Silva. O léxico dos jogos e diversões infantis no corpus do Projeto ALiB: visitando o Falar Nordestino, 2018, 207 f. Dissertação (Mestrado em Língua e Cultura), Universidade Federal da Bahia, Salvador, 2018.

SANTOS, Leandro Almeida dos. Brincando pelos caminhos do Falar Fluminense, 2016, 197f. Dissertação (Mestrado em Língua e Cultura), Universidade Federal da Bahia, Salvador, 2016.

SAPIR, Edward. Língua e ambiente. In: SAPIR, Edward. A linguística como ciência. Ensaios. Tradução de Joaquim Mattoso Câmara Jr. Rio de Janeiro: Livraria Acadêmica, 1961. p. 43-62.

TELES, Ana Regina T. F.; RIBEIRO, Silvana S. C. Apresentando a cartografia aos linguistas: o Projeto ALiB. In: MOTA, Jacyra Andrade; CARDOSO, Suzana Alice Marcelino (org.). Documentos 2. Projeto Atlas Lingüístico do Brasil. Salvador: Quarteto, 2006. p. 207-226.

Obras citadas no Tesouro do léxico patrimonial galego e português (TLPGP) e utilizadas na descrição dos dados ${ }^{26}$

${ }^{26}$ Optamos por manter a citação dos trabalhos originados do Tesouro como referenciados naquela base de dados. Estão apresentados na sua língua de origem, respeitando texto original. 
ALTINO, Fabiane Cristina (2001): Pelos caminhos da geolinguística paranaense: um estudo do léxico popular de Adrianópolis. Dissertação de Mestrado em Letras. Londrina: Universidade Estadual de Londrina.

ALTINO, Fabiane Cristina (2007): Atlas lingüístico do Paraná - II - ALPR II. Londrina. Tese de Doutorado. Londrina: Universidade Estadual de Londrina.

BAAMONDE TRAVESO, Gloria (1977): A fala das parroquias de Arante e Cedofeita. Memoria de Licenciatura. Universidade de Santiago de Compostela.

BABARRO GONZÁLEZ, Xoán (2003): Galego de Asturias. Delimitación, caracterización e situación sociolingüística. A Coruña: Fundación Pedro Barrié de la Maza, vol. II, 333-459.

BRAGA, Franklim Costa (1971): Quadrazais. Etnografia e Linguagem. Dissertação de Licenciatura. Universidade de Lisboa.

BRAVO CRIADO, Xosé Antón (1984): A fala do Val do Toxa. Memoria de Licenciatura. Universidade de Santiago de Compostela.

CASTRO CASTEDO, Xosé Manuel (1986): O galego en Queizán (O Corgo). Memoria de Licenciatura. Universidade de Santiago de Compostela.

CORTÉS VÁZQUEZ, Luis (1954): El dialecto galaico-portugués hablado en Lubián (Zamora). Toponimia, textos y vocabulario. Salamanca: Universidad de Salamanca.

CRISTIANINI, Adriana Cristina (2007): Atlas semântico-lexical da região do Grande ABC. Tese de Doutoramento. Universidade de São Paulo.

DIAS, Marcelo Pires (2015): Banco de Dados do Atlas Geossociolinguístico Quilombola do Nordeste do Pará ( $A G Q U I N P A)$. Santiago de Compostela: Instituto da Lingua Galega.

EBS REBORDOSA (2020): Língua, património e conhecimento tradicional. Jogos e brinquedos. Ano lectivo 2019-2020. Coord. Ivone Monteiro. Escola Básica e Secundária de Rebordosa, Portugal.

ENCARNAÇÃO, Márcia Regina Teixeira da (2010): Atlas semântico-lexical de Caraguatatuba, Ilhabela, São Sebastião e Ubatuba - municípios do Litoral Norte de São Paulo. Tese de Doutoramento. Universidade de São Paulo.

FIGUEIREDO JR., Selmo Ribeiro (2018): Atlas linguístico pluridimensional do português paulista: níveis semântico-lexical e fonético-fonológico do vernáculo da região do Médio Tietê. Tese de Doutorado. Faculdade de Filosofia, Letras e Ciências Humanas. Universidade de São Paulo.

FRAIZ BARREIRO, María de los Ángeles (1974): El léxico de Codeseda. Memoria de Licenciatura. Universidade de Santiago de Compostela.

GÓMEZ GALLEGO, Ana et al. (2017): Xogos tradicionais. Banco de datos: enquisas da materia Dialectoloxía Galega, 2016-2017. Coord. Rosario Álvarez. Universidade de Santiago de Compostela.

GONZÁLEZ GONZÁLEZ, Margarita (2002): El gallego hablado de Cangas de Morrazo. Tese de doutoramento. Universidad de Oviedo. 
LÓPEZ TABOADA, Carme (1978): El habla de la comarca de Sobrado de los Monjes. Memoria de Licenciatura. Universidade de Santiago de Compostela.

MAIA, Maria Lúcia Borba e (1965): O falar da ilha Terceira. Dissertação de Licenciatura. Universidade de Lisboa.

MATIAS, Maria de Fátima de Rezende F. (1974): Bilinguismo e níveis sociolinguísticos numa região luso-espanhola (Concelhos de Alandroal, Campo Maior, Elvas e Olivença). Dissertação de Licenciatura. Universidade de Coimbra. [ed. de id. (1984): Bilinguismo e níveis sociolinguísticos numa região luso-espanhola (Concelhos de Alandroal, Campo Maior, Elvas e Olivença). Separata de Revista Portuguesa de Filologia, vols. XVIII e XIX].

MEDEIROS, Maria de Jesus Chichorro de (1964): A linguagem micaelense em alguns dos seus aspectos. Dissertação de Licenciatura. Universidade de Lisboa.

PEREIRA, Maria Fernanda Afonso Alves (1970): O falar de Soajo. Dissertação de Licenciatura. Universidade de Lisboa.

RODRÍGUEZ LAGO, Ma Carmen (1974): Léxico dialectal y costumbres de Porto. Memoria de Licenciatura. Universidade de Santiago de Compostela.

ROXÍOS, Quique (2010): "A carabañola, a billarda", Espacio de Quique Roxíos. El ruxe ruxe del molín de Sanzo. https://quiqueroxios.wordpress.com/2010/03/03/a-carabanola-abillarda/ [consulta: 24/04/2018].

VÁZQUEZ SOMOZA, Xosé Luís (1986): O galego en Zolle (Guntín). Memoria de Licenciatura. Universidade de Santiago de Compostela

Atlas Linguísticos citados no Tesouro do léxico patrimonial galego e português (TLPGP) e que não foram utilizadas na descrição dos dados ${ }^{27}$

AGUILERA, Vanderci de Andrade (1987): Aspectos lingüísticos da fala londrinense: esboço de um atlas lingüístico de Londrina. Vol. II: Cartas Linguísticas Lexicais. Dissertação de Mestrado em Letras. Universidade Estadual Paulista. Curitiba: Conselho de Ciência e Tecnologia do Paraná - CONCITEC.

AGUILERA, Vanderci de Andrade (1990): Atlas linguístico do Paraná. Tese de Doutorado em Letras. Assis-SP: Universidade Estadual Paulista. [= Atlas linguístico do Paraná. (1994) Curitiba: Imprensa Oficial do Estado do Paraná / Londrina: Universidade Estadual de Londrina].

ALMEIDA, Edilene Maria Oliveira de (2009): Atlas Linguistico da Mata Sul de Pernambuco. Dissertação de Mestrado. Universidade Federal da Paraíba.

ARAGÃO, Maria do Socorro Silva de / MENEZES, Cleusa Bezerra de (1984): Atlas lingüístico da Paraíba. V. Vols. 1 e 2. Brasília: CNPq/UFPB.

${ }^{27}$ Optamos por manter a citação dos trabalhos originados do Tesouro como referenciados naquela base de dados. Estão apresentados na sua língua de origem, respeitando texto original. 
BESSA, José Rogério Fonetele (org.) (2010): Atlas Lingüístico do Ceará. Fortaleza: Universidade Federal do Ceará.

CARDOSO, Suzana Alice M. (2005): Atlas lingüístico de Sergipe II. Salvador: EDUFBA.

CUBA, Marigilda Antonio (2009): Atlas Linguístico da Mesorregião Sudeste de Mato Grosso. Dissertação (Mestrado em Estudos de Linguagens) - Universidade Federal de Mato Grosso do Sul, Campo Grande-MS.

FABRIS, Simone Rosana (1997). Esboço de um atlas lingüístico de Tamarana. Monografia de Especialização em Língua Portuguesa. Londrina: Universidade Estadual de Londrina.

FERREIRA, Carlota et al. (1987): Atlas lingüístico de Sergipe. Salvador: Instituto de Letras / Fundação Estadual de Cultura de Sergipe.

LIMA, Fabiana dos Santos (2009): Atlas Linguistico de Iguatu. Dissertação de Mestrado. Universidade Federal do Ceará.

PEREIRA, Maria das Neves (2007): Atlas Geolingüístico do Litoral Potiguar. Tese de Doutorado. Universidade Federal do Rio de Janeiro.

PIZOLATO, Tania Mara de Podestá (1997): Esboço de um atlas lingüístico de Centenário do Sul. Monografia de Especialização em Língua Portuguesa. Londrina: Universidade Estadual de Londrina.

REIS, Regiane Coelho Pereira (2006): Atlas Lingüístico do município de Ponta Porã-MS: um registro das línguas em contato na fronteira do Brasil com o Paraguai. Dissertação (Mestrado em Letras) - Universidade Federal de Mato Grosso do Sul, Três Lagoas-MS.

ROMANO, Valter Pereira (2012): Atlas geossociolinguístico de Londrina: um estudo em tempo real e tempo aparente. Dissertação de Mestrado em Estudos da linguagem, Londrina: Universidade Estadual de Londrina.

ROSSI, Nelson / Carlota Ferreira / Dinah Isensee (1963): Atlas prévio dos falares baianos. Rio de Janeiro: INL.

SANCHES, Romário Duarte (2015): Variação lexical nos dados do projeto Atlas Geossociolinguístico do Amapá. Dissertação de Mestrado. Programa de Pós-graduação em Letras. Universidade Federal do Pará.

SOARES, Rita de Cássia da Silva (2012): Atlas semântico-lexical da Região Norte do Alto Tietê - ReNAT-São Paulo. Tese de Doutoramento. Universidade de São Paulo.

Nota do editor:

Artigo submetido para avaliação em: 10 de abril de 2021.

Aprovado em sistema duplo cego em: 22 de julho de 2021. 